\title{
Change of State Verbs: Implications for Theories of Argument Projection $^{1}$
}

\author{
MALKA RAPPAPORT HOVAV \\ The Hebrew University of Jerusalem
}

\author{
BETH LEVIN \\ Stanford University
}

\section{Introduction}

Recent work in argument expression has focused on verbs showing multiple argument projection options, often with concomitant shifts in aspectual classification or assignment of so-called "aspectual roles" (e.g., measure or incremental theme). Two examples of these phenomena are given in (1)-(2).

(1) a. Dana read the book. (telic)

b. Dana read from the book. (atelic)

(2) a. Kerry wiped the table clean. (the table is the measure)

b. Kerry wiped the crumbs off the table. (the crumbs is the measure)

The ubiquity of such verbs has prompted theories of argument projection which adopt one or both of the following hypotheses:

(3) a. HYPOTHESIS I: Argument projection is aspectually determined.

b. HYPOTHESIS II: Argument expression is not lexically determined.

The first hypothesis, that argument projection is aspectually driven, finds perhaps its earliest explicit statement as Tenny's (1987, 1992, 2994) Aspectual Interface Hypothesis and has subsequently been quite widely adopted (e.g., Arad 1998, Borer 1998). Proponents of this hypothesis often establish a connection between direct objecthood and notions such as telicity (van Hout 1996, Ritter \& Rosen 1998), incremental theme (Rothstein 2000), measure (Tenny 1994), or subject of result (Borer 1998). This hypothesis is tied explicitly to the phenomena in (1) and (2) by van Hout's 1996 proposal that argument alternations represent

\footnotetext{
${ }^{1}$ We thank audiences at BLS and the Syntax of Aspect Workshop at Ben Gurion University of the Negev for their questions and comments. This work was supported in part by Israel Science Foundation Grant 832-00 to Rappaport Hovav.
} 
event type-shifting. Indeed, many alternations can be so understood. Arguments that are alternately expresses as direct object and oblique, e.g., (1), reflect alternations between telic and atelic uses of verbs, while alternate choices of direct object, e.g., (2), are a reflection of alternate choices of the argument which determines the telicity of the sentence.

The pervasiveness of multiple argument realization brought the assumption that verbs lexically determine the expression of their arguments under renewed scrutiny. Various researchers, starting with Hoekstra \& Mulder (1990), proposed an alternative hypothesis: argument expression is not lexically determined (our Hypothesis II). Proponents of extreme versions of this hypothesis argue that arguments are projected freely onto syntax, with verbs being unspecified for those components of meaning that determine argument expression. The interpretation of a sentence is derived from the meaning of the verb in combination with the way in which its arguments are projected. Although lip service is often paid to the idea that a verb's meaning must be compatible with syntactically determine meaning (Ghomeshi \& Massam 1995), it is the free projection of arguments which is stressed and put to work, while the explication of compatibility is taken to be trivial.

The ideas embodied in Hypotheses I and II go together naturally. In fact, many current theories of argument realization assume a conjunction of the two: aspectual properties are compositionally derived in syntax (Arad 1998, Borer 1998, Ritter \& Rosen 1998). Verbs project their arguments freely onto syntax; the aspectual roles of arguments and the aspectual interpretation of the sentence are determined by the nature of this projection: aspectual composition is EFFECTED by checking or interpreting aspectual features in functional projections. This represents a departure from traditional theories of aspectual composition, which assume argument expression merely reflects aspectual composition.

Although much recent work incorporates the conjunction of the two hypotheses, they represent two distinct issues: whether argument expression is aspectually driven and whether argument expression is lexically or syntactically determined. It is possible to argue that argument projection is lexically determined and aspectually driven (e.g., Tenny 1987, 1992, 1994) or to argue that projection is not completely lexically determined but not completely aspectually driven either (e.g., Jackenoff 1990). We argue against each individual hypothesis, as well as against their conjunction. We do this through a close examination of the argument expression properties of change of state (COS) verbs-verbs lexicalizing a change of state - and a comparison of these properties with those of aspectually-related verbs. We show that although argument expression is not entirely lexically determined, as stressed in Butt \& Geuder (1998b), a verb's lexicalized meaning is nonetheless important to determining or constraining its argument expression options (see also Erteschik-Shir \& Rapoport 2000). Furthermore, the relevant facets of meaning don't correspond to well-known aspectual notions. We begin by showing that COS verbs, though uniform in argument expression, aren't uniform aspectually. 


\section{Uniformity in argument expression is not aspectual uniformity}

COS verbs have long been known to exhibit distinctive argument realization properties (Fillmore 1970, 1977, Levin 1993). What is most striking are the severe constraints on their argument realization options. In particular, the patient argument - the entity undergoing the change of state - must be expressed and can only be expressed as a direct object, as we now illustrate.

Although other verbs are found in any of a number of frames with an argument left unexpressed, COS verbs are never found in such frames without their patient. Specifically, they aren't found with unspecified objects, as in (4), nor are they found in nonsubcategorized NP resultatives, as in (5), nor do they allow out-prefixation, as in (6). These last two frames resemble the unspecified object frame in that the verb's normal direct object is left unexpressed. ${ }^{2}$

(4) $*$ Pat broke/dimmed.

(5) a. $*$ My kids broke me into the poorhouse.

b. $*$ The stagehand dimmed the scene dark.

a. * The two-year old outbroke the three-year old.

b. *The stagehand outdimmed the director.

Furthermore, the patient must be the direct object and cannot be an oblique, as in (7). Consequently, COS verbs aren't found in object alternations in which the argument which is normally the direct object "vacates" its position for another NP, being expressed instead as an oblique, as in (8).

(7) a. Alex broke the vase $/ *$ Alex broke at the vase.

b. Sam dimmed the lights/*Sam dimmed at/from the lights.

a. Kelly broke my arm

b. $*$ Kelly broke me on the arm. (cf. Kelly hit me on the arm.)

The lack of argument alternation also emerges when the interpretation of the sentence pair in (9) with break is compared to that of the superficially parallel sentence pair with the non-COS verb hit in (10). As Fillmore (1977) points out, the hit sentences, as near paraphrases, qualify as an argument alternation. The break sentences, however, are not near paraphrases; rather, in each the direct object is understood as the patient.

\footnotetext{
${ }^{2}$ Goldberg (2001) points out that COS verbs are sometimes found with unspecified objects or in resultatives with nonsubcategorized NPs. However, as Goldberg herself notes, this happens with COS verbs only in generic or habitual contexts, while other verbs appear in these constructions even outside of these contexts. Thus, COS verbs are special, though such data must be accommodated within a full theory of argument realization
} 
(9) a. Sam broke the fence with the stick.

b. Sam broke the stick against the fence.

(10) a. Sam hit the fence with a stick.

b. Sam hit a stick against the fence. (Fillmore 1977:75)

These differences are another manifestation of the constraint that the patient of a COS verb must be its direct object. These examples are noteworthy in another way. Although the stick is associated with an entailment of change of location which allows an argument to qualify for direct objecthood (cf. the acceptability of (10b)), as an argument of break, it can only be the direct object if it is also the patient.

This restricted behavior is unexpected from the perspective of Hypothesis II, which is often understood to mean that arguments project freely. Nonetheless, if argument expression is taken to be aspectually determined, the uniformity in argument expression of $\mathrm{COS}$ verbs might be attributed to a shared aspectual property. However, COS verbs lack a uniform aspectual characterization, at least in terms of traditional notions. When COS verbs take a definite, singular object, they can be necessarily telic (e.g., break, dry, explode, flatten, freeze) or either telic or atelic (e.g., cool, darken, dim, widen). Variable telicity, in fact, is the distinguishing property of the much-discussed set of COS verbs known as "degree achievements" (Abusch 1986, Dowty 1979, Hay, Kennedy \& Levin 1999). Furthermore, when telic, some COS verbs are punctual (e.g., break, crack, explode), while others are durative (e.g., cool, dim, dry, freeze, widen). Despite these differences in aspectual potential, all COS verbs show the same behavior. We illustrated the properties of COS verbs using the verbs break and dim, which were chosen because they differ along aspectual dimensions. First, break is necessarily telic, while dim - a degree achievement - may be telic or atelic. Second, break is punctual and dim is durative. Yet both verbs show the same argument realization patterns.

COS verbs, then, share a constrained set of argument projection possibilities, but aren't uniform aspectually. These observations suggest that lexical aspectual classification alone does not determine argument expression. Hypothesis I is undermined, unless some other aspectual property can be shown to unify the class of COS verbs. We now address this issue.

\section{Probing the contribution of aspect to argument expression further}

\subsection{Verbs with incremental themes show different argument projections}

Much current work suggests that the aspectual notion most relevant to argument projection is "incremental theme" (Dowty 1991) or one of its relatives. Krifka (1992) suggests that incremental theme verbs have an argument that is lexically associated with the property of "mapping to events", that is, parts of the entity denoted by that argument can be mapped onto parts of the event denoted by the verb. For example, when you drink a glass of water, the event is half over when half 


\section{Change of State Verbs}

the water has been consumed. Therefore, Hypothesis I might still be on the right track, with the aspectual notion of incremental theme unifying the verbs showing the pattern of behavior demonstrated by COS verbs. However, as we now show, though the patient of a COS verb acts as an incremental theme, a comparison of COS verbs with other incremental theme verbs suggests that it is not the patient as incremental theme which determines the argument expression profile of COS verbs.

First, we comment on terminology. The term "incremental theme" was originally applied by Dowty (1991) to the argument of certain predicates involved in defining a homomorphism from its own physical extent to the temporal progress of the event it participates in. By this definition, verbs like read, write, and eat are incremental theme verbs. Dowty also meant this term to cover the patient argument of $\operatorname{COS}$ verbs, but its application to these verbs needs clarification. The sentence Matt closed the door halfway doesn't entail that half the door was closed, but that the door was halfway closed. The mapping involves a property of the door and not the door's own physical extent. Recent studies (Hay et al. 1999, Krifka 1998, Ramchand 1997, Tenny 1992, 1994) have found ways to provide parallel aspectual analyses to COS verbs and traditional incremental theme verbs. Patients of COS verbs and traditional incremental themes are associated with some property - a scalar property of the object lexicalized by their verb for the former and the physical extent of the object for the latter - which serves as a scale for measuring the temporal progress of the entire event. When the event describes a specified degree of change on the scale, it is telic, and when it describes an unspecified degree of change, it is atelic (Kennedy \& Levin 2001). The objects of both traditional incremental theme verbs and COS verbs, then, share an identical aspectual role, which we continue to call "incremental theme," in that both verb types are associated with a scale for measuring the event's progress.

The parallelism can be brought out further. It is well-known that the quantization of the direct object of a traditional incremental theme verb determines the telicity of its sentence, as in (11). The physical extent of the object provides the scale for measuring the progress of such events. If the object is quantized, its physical extent is specified, as is the change on the associated scale, and the sentence is telic. If the object isn't quantized, the scale lacks a specified endpoint, the change on this scale is unspecified, and the sentence is atelic.

a. Dana read poetry for $/ *$ in an hour. (nonquantized object; atelic)

b. Dana read the newspaper for/in an hour. (quantized object; telic)

The telicity of a sentence with a COS verb also depends on the nature of the change on the associated scale. The relevant change, however, is determined by a scalar property lexicalized in the verb, not directly by the quantized nature of the direct object. The verb warm is associated with a temperature scale, and a sentence with this verb is telic if the change in temperature is specified and atelic otherwise, as in (12); see Kennedy \& Levin (2001) for more discussion. 
(12) a. Sandy warmed the solution for three minutes. (atelic)

b. Sandy warmed the solution five degrees in three minutes. (telic)

Although parallel aspectual analyses are available for both verb types, traditional incremental theme verbs are more flexible in their argument expression properties than COS verbs. First, the argument that serves as the incremental theme when these verbs are used transitively need not be expressed. These verbs permit unspecified objects, as in (13); they also allow nonsubcategorized NP objects, either in a resultative construction or via out-prefixation, as in (14) and (15) (cf. (4)-(6)). Furthermore, this same argument need not be expressed as direct object, as in (16), though it is then no longer an incremental theme (cf. (7)). Thus, verbs that have an incremental theme do not show uniform argument expression properties.

(13) Dana read/ate/wrote.

(14) a. The teacher read us into a stupor.

b. My kids ate me into the poorhouse.

c. I wrote myself out of a job.

(15) Pat outread/outate/outwrote Chris.

(16) a. Dana read the book./Dana read from the book.

b. Chris ate the apple./Chris ate from/of the apple.

c. I wrote my book./I wrote at my book.

\subsection{Comparison with potential incremental theme verbs}

Verbs like read, write, and eat, which invariably allow their direct object to be interpreted as an incremental theme, may be contrasted with potential - or "latent" (Tenny 1992:20) - incremental theme verbs, a class we exemplify with surface contact verbs (e.g., comb, rub, scratch, shovel, sweep, wipe). Such verbs do not require their "normal" direct object, even when quantized, to be analyzed as an incremental theme. ${ }^{3}$ That is, in the presence of a quantized object, they may pattern as telic or atelic with respect to standard telicity tests, as in (17) and (18).

(17) a. Lee scrubbed the tub for hours. (atelic)

b. Lee scrubbed the tub in three minutes flat. (telic)

\footnotetext{
${ }^{3}$ In fact, traditional incremental theme verbs (e.g., read, write, eat) also show atelic readings with quantized objects (Hay et al. 1999, van Hout 1996, Tenny 1994). Pat read the newspaper for an hour is certainly marginally acceptable, and some speakers even find it fully acceptable. In contrast, speakers agree that a potential incremental theme verb with a quantized object is perfectly acceptable with an atelic interpretation.
} 


\section{Change of State Verbs}

(18) a. Lee is scrubbing the tub and has scrubbed it for the last hour. (atelic)

b. Lee is scrubbing the tub and still hasn't finished. (telic)

These verbs may be atelic because they describe processes that can be applied indefinitely to a surface. Their telic uses most likely arise because the processes they describe are usually carried out with specific intended results, though these verbs do not entail the achievement of any result (Talmy 2000). The intended result gives rise to an associated scale. With scrub two scales are possible. One is provided by the tub's surface area, with the process being complete when the scrubbing has covered the entire tub. Alternatively, the desired result may be a clean tub, with the scale being one of cleanliness. On either interpretation, the object is an incremental theme: on the former, the event is over when the whole tub is scrubbed, and on the latter, the event is over when the tub's state reaches the point of cleanliness.

The "normal" direct object of surface contact verbs is considered a location in a traditional semantic role analysis, but these verbs may also take as their object an argument describing material found at this location (Levin \& Rappaport Hovav 1991), giving rise to an argument alternation, as in (19). When the material is the object, it too can be the incremental theme by virtue of its physical extent: it determines telicity when quantized, as in (20).

(19) Lee scrubbed the tub./Lee scrubbed the stains off the tub.

(20) a. Lee scrubbed blood off the tub for ten minutes. (atelic)

b. Lee scrubbed the blood off the tub in ten minutes. (telic)

Surface contact verbs need not express either the material or the location. They don't require the expression of an object, as in (21), and can take nonsubcategorized NP objects, either in resultative constructions or via out-prefixation, as in (22)-(23).

(21) Lee swept/wiped/scrubbed.

(22) Cinderella scrubbed her fingers to the bone.

(23) a. Cinderella outswept/outscrubbed her stepsisters.

b. This hairdresser outcombed that one.

Finally, potential incremental theme verbs don't impose semantic restrictions on their direct object: it can be the material, as in Lee scrubbed the stains, the location as in Lee scrubbed the tub, or a nonargument, as in (22)-(23). The material and location arguments, though potential incremental themes, can be expressed as obliques as well as objects, though the oblique expression of locations is dispreferred.

(24) a. Kerry scrubbed at the stain. (material)

b. ?Kerry scrubbed at the counter, (location) 
(25) a. Lee scratched at the mosquito bites. (material)

b. ? Lee scratched at her arm. (location)

In conclusion, COS verbs share an important aspectual property - an incremental theme - with other verbs, but don't share their argument expression properties.

\subsection{Lexical influences on the choice of incremental theme}

Traditional and potential incremental theme verbs have been used to support the conjunction of Hypotheses I and II: verbs are not lexically specified for an incremental theme and an argument or other NP projected onto the direct object position (or whatever its formal definition is taken to be, e.g., Spec, AgrO) is interpreted as the incremental theme. Indeed, the argument or other NP chosen as the object of these verbs is construed (or construable) as their incremental theme.

Although this is true of some verbs, it isn't true of COS verbs. As discussed in section 2.1, the patient of a COS verb MUST be construed as the incremental theme of its sentence, and no other argument or NP may be so construed. COS verbs, at least, seem to have lexically specified incremental themes. Construal as an incremental theme, then, isn't always the result of the free projection of an argument onto a specific syntactic position.

If some verbs are lexically specified as taking a particular argument as incremental theme, while others are not, it may be possible to maintain a form of $\mathrm{Hy}$ pothesis I, while abandoning Hypothesis II: with COS verbs, the entity associated with the change of state entailment is lexically constrained to be the incremental theme, with their limited argument projection options following from this assumption. This appears to be the gist of Dowty's (1991) suggested analysis of these verbs. The other classes of incremental theme verbs would not lexically specify a particular argument as incremental theme and, thus, would show more argument expression options. On this approach, a lexicaliy specified aspectual property still determines argument expression.

This proposal, however, is predicated on two assumptions: incremental themes are constrained to be direct objects and in the presence of an incremental theme no other argument may be the direct object. However, neither assumption is correct. First, Dowty (1991:570) and Jackendoff (1996:313) have pointed out incremental themes which are not direct objects, as in The train crossed the border and The parade passed the mayor. Second, in some instances one argument may serve as an incremental theme even when another is expressed as direct object. This situation is found in the dative alternation, shown by verbs of transfer. With these verbs, the theme normally determines telicity, as in (26).

a. Dana read poetry to employees/her niece for an hour. (atelic)

b. Dana read the story to employees/her niece in an hour. (telic)

Despite Arad's (1998) claim that the dative alternation is aspectually motivated, the theme is still the incremental theme when the recipient becomes the direct object in 


\section{References}

Abusch, Dorit. 1986. Verbs of change, causation, and time. Report CSLI-86-50, Center for the Study of Language and Information, Stanford University.

Arad, Maya. 1998. VP-structure and the syntax-lexicon interface. PhD dissertation, University College London.

Baker, Mark C. 1997. Thematic roles and syntactic structure. In L. Haegeman (ed.) Elements of Grammar, 73-137. Dordrecht: Kluwer.

Borer, Hagit. 1998. Passive without theta grids. In S.G. Lapointe, et. al (eds.) Morphological Interfaces, 60-99. Stanford, CA: CSLI Publications.

Butt, Miriam \& Willi Geuder (eds.). 1998a. The projection of arguments: Lexical and compositional factors. Stanford, CA: CSLI Publications.

Butt, Miriam \& Willi Geuder. 1998b. Introduction. In Butt \& Geuder (eds.), 1-20.

Dowty, David. 1979. Word meaning and Montague Grammar. Dordrecht: Reidel.

Dowty, David. 1991. Thematic proto-roles and argument selection. Language 67: 547-619.

Erteschik-Shir, Nomi \& T.R. Rapoport. 2000. Bare aspect: A theory of syntactic projection. International Round Table 'The Syntax of Tense and Aspect', Université de Paris 7.

Fillmore, Charles J. 1970. The grammar of hitting and breaking. In Roderick A. Jacobs \& Peter S. Rosenbaum (eds.) Readings in English Transformational Grammar, 120-133. Waltham, MA: Ginn.

Fillmore, Charles J. 1977. The case for case reopened. In P. Cole \& J.M. Sadock (eds.) Grammatical relations, 59-81. New York: Academic Press.

Ghomeshi, Jila \& Diane Massam. 1995. Lexical/syntactic relations without projection. Linguistic Analysis 24: 175-217.

Goldberg, Adele E. 2001. Patient arguments of causative verbs can be omitted: The role of information structure in argument distribution. Language sciences 23 : 503-524.

Hale, Ken \& Jay Keyser. 1998. The basic elements of argument structure. MIT working papers in linguistics 32: 73-118.

Hay, Jennifer, Chris Kennedy \& Beth Levin. 1999. Scalar structure underlies telicity in 'degree achievements'. SALT 9: 127-144.

Hoekstra, Teun \& René Mulder. 1990. Unergatives as copular verbs: Locational and existential predication. The Linguistic Review 7: 1-79.

van Hout, Angeliek. 1996. Event semantics of verb frame alternations. PhD dissertation, Tilburg University.

Jackendoff, Ray S. 1976. Toward an expła7fatory semantic representation. Linguistic inquiry 7: 89-150.

Jackendoff, Ray S. 1983. Semantics and cognition. Cambridge, MA: MIT Press.

Jackendoff, Ray S. 1990. Semantic structures. Cambridge, MA: MIT Press.

Jackendoff, Ray S. 1996. The proper treatment of measuring out, telicity, and perhaps even quantification in English. NLLT 14: 305-354. 
of state MUST be the direct object and MUST be the incremental theme; in contrast, as we now show, an entity which is lexically entailed to undergo movement CAN be a direct object, but need not be, and it need not be an incremental theme.

We make this point with the locative alternation verbs splash and spray, which lexically entail the movement of a liquid substance, i.e. they take an argument that qualifies as a theme of change of location. This argument need not be expressed, as in (28), nor does it have to be direct object, as in (29).

(28) Brett splashed/sprayed.

(29) a. Brett sprayed/splashed water on the plants.

b. Brett sprayed/splashed the plants with water.

c. ?Brett sprayed/splashed at the plants.

Although the patient of a COS verb MUST be that verb's incremental theme, the theme of a verb entailing change of location need not be that verb's incremental theme. As locative alternation verbs, splash and spray, allow either a location or a theme of change of location as their direct object. When the location is the object, these verbs pattern like latent incremental theme verbs since the telicity of their sentence isn't necessarily determined by the quantized nature of the object, but it may be (Dowty 1991, Jackendoff 1996).

(30) a. Bill sprayed the wall with paint for five minutes. (atelic)

b. Bill sprayed the wall with paint in an hour. (telic)

It is noteworthy that the location is a potential incremental theme, though these verbs also have an argument that is a theme of a change of location. COS verbs, in contrast, do not allow their patient argument to abdicate incremental themehood to another argument. The special properties of COS verbs, then, are characteristic of just this semantic class and do not generalize to other semantic classes of verbs, even one that has been given a parallel semantic analysis.

\section{Conclusion}

The argument expression possibilities of COS verbs appear to be determined by a nonaspectual, lexicalized property - change of state - and can't be handled by purely aspectual nonlexical theories of argument projection. Traditional aspectual classes don't constitute natural classes from the perspective of argument expression.

These data pose problems for approaches which take aspectual notions as the sole determinants of argument expression. They support a theory, as in Rappaport Hovav \& Levin (1998), in which constants typed by ontological category are lexically associated with nonaspectually defined event structures, and these, in turn, constrain argument projection, as also espoused by Hale \& Keyser (1998).

sions, it seems that the entailment of a change of state and the entailment of a change of location for an argument constrain argument projection in different ways. 


\section{Change of State Verbs}

the double object construction. In (27) the recipient is the first object - taken to be the double object construction's instantiation of a direct object - and the theme, though the second object, still determines telicity.

(27) a. Dana read her niece poetry for an hour. (atelic)

b. Dana read her niece the story in an hour. (telic)

Therefore, this alternation in direct object choice cannot be aspectually driven (see also Baker 1997), contra Hypothesis I, and a de facto incremental theme "relinquishes" its position as direct object to another argument. Recently, some researchers have proposed that the recipient in a double object construction is not an underlying direct object (the theme is), but rather has become the specifier of a higher functional projection (Baker 1997). Although this analysis is meant to explain why recipients do not show the full range of direct object properties (Baker 1997, Maling 2001), this analysis is incompatible with approaches to argument projection that adopt the conjunction of Hypotheses I and II. On these approaches, movement into a higher functional projection is supposed to be associated with aspectual shifts, while "underlying" direct objects (i.e., complements of V) are explicitly not associated with these properties. Yet, on Baker's analysis, the theme, which can act as an "incremental theme" is the "underlying" direct object, while the recipient moves to a higher functional projection.

Finally, there are some incremental themes which aren't explicitly expressed. For example, the direct object in out-prefixation sentences is not an incremental theme. In Pat outate Chris, parts of Chris do not correspond to parts of the outeating event. Rather, the incremental theme seems to be the amount of eating that Pat did (e.g., Pat was halfway towards outeating Chris), and this notion is not expressed.

Since the incremental theme of a sentence need not be its direct object, the fact that the patient of a COS verb must be expressed as direct object can't be attributed to its having a lexically specified incremental theme. The distinctive argument expression properties of COS verbs appear NOT to follow from any aspectual property of these verbs, whether lexically specified or not.

\section{Comparison with verbs having a change of location entailment}

Most researchers draw a parallel between themes of changes of location and patients of changes of state. These parallels were first drawn in localist theories (Jackendoff 1976, 1983), which conceptualize changes of state as instances of changes of location. ${ }^{4}$ As discussed in section 2.1 , an entity lexically entailed to undergo a change

\footnotetext{
${ }^{4}$ Jackendoff (1990) proposes that changes of state and changes of location have different predicates in their conceptual structure. He thereby moves away from the strict versions of the Localist $\mathrm{Hy}$ pothesis adopted in his earlier work $(1976,1983)$. More recently, this parallel has been used to unify these arguments under the same aspectual concept (Hay et al. 1999, Levin \& Rappaport Hovav 1995, Ramchand 1997, Tenny 1992, 1994). Although drawing the parallel may be useful for determining aspectual properties of verbs and for understanding certain kinds of metaphorical meaning exten-
} 
Kennedy, Chris \& Beth Levin. 2001. Telicity corresponds to degree of change. Handout, 75th Annual LSA Meeting, Washington, DC.

Krifka, Manfred. 1992. Thematic relations as links between nominal reference and temporal constitution. In Sag \& Szabolcsi (eds.), 29-54.

Levin, Beth. 1993. English verb classes and alternations. Chicago, IL: University of Chicago Press.

Levin, Beth. 1999. Objecthood: An event structure perspective. CLS 35; Part 1: 223-247.

Levin, Beth and Malka Rappaport Hovav. 1991. Wiping the slate clean: A lexical semantic exploration. Cognition 41: 123-151.

Levin, Beth and Malka Rappaport Hovav. 1995. Unaccusativity: At the SyntaxLexical Semantics Interface. Cambridge, MA: MIT Press.

Maling, Joan. 2001. Dative: The heterogeneity of the mapping among morphological case, grammatical functions, and thematic roles. Lingua 111: 419-464.

Ramchand, Gillian C. 1997. Aspect and predication. Oxford: Clarendon Press.

Rappaport Hovav, Malka \& Beth Levin. 1998. Building verb meanings. In Butt \& Geuder (eds.), 97-134.

Ritter, Elizabeth \& Sara T. Rosen. 1998. Delimiting events in syntax. In Butt \& Geuder (eds), 135-164.

Rothstein, Susan. 2000. Secondary predication and aspectual structure. Approaching the grammar of adjuncts. ZAS Papers in Linguistics 17: 241-264.

Sag, Ivan and Anna Szabolcsi (eds.). 1992. Lexical matters. Stanford, CA: CSLI.

Talmy, L. 2000. Towards a cognitive semantics II. Cambridge, MA: MIT Press.

Tenny, Carol L. 1987. Grammaticalizing aspect and affectedness. PhD dissertation, MIT.

Tenny, Carol L. 1992. The Aspectual Interface Hypothesis. In Sag \& Szabolcsi (eds), 1-27.

Tenny, Carol L. 1994. Aspectual roles and the syntax-semantics interface. Dordrecht: Kluwer.

(Rappaport Hovav)

Department of English

The Hebrew University of Jerusalem

91905 Jerusalem, Israel

(Levin)

Department of Linguistics

Stanford University

Stanford, CA 94305-2150

mhovav@mscc.huji.ac.il

bclevin@stanford.edu 